\title{
BMJ Open Level of knowledge, attitude and practice towards diabetes among nationals and long-term residents of Qatar: a cross-sectional study
}

Kholoud Ateeq Al-Mutawaa, ${ }^{1}$ Aiman Hussein Farghaly (D) , ${ }^{2}$ Rehana Nasir, ${ }^{1}$ Alma Malvar Loares (D) , Ioanna Skaroni, ${ }^{1,3}$ Mohammed Al-Thani, ${ }^{1}$ Abdul-Badi Abou-Samra ${ }^{1,3}$

To cite: Al-Mutawaa KA, Farghaly AH, Nasir R, et al. Level of knowledge, attitude and practice towards diabetes among nationals and long-term residents of Qatar: a crosssectional study. BMJ Open 2022;12:e052607. doi:10.1136/ bmjopen-2021-052607

- Prepublication history for this paper is available online. To view these files, please visit the journal online (http://dx.doi. org/10.1136/bmjopen-2021052607).

Received 29 April 2021 Accepted 20 January 2022

Check for updates

(c) Author(s) (or their employer(s)) 2022. Re-use permitted under CC BY-NC. No commercial re-use. See rights and permissions. Published by BMJ.

${ }^{1}$ Public Health Department, Ministry of Public Health, Doha, Qatar

${ }^{2}$ General Authority of Healthcare, Ismailia, Egypt

${ }^{3}$ Qatar Metabolic Institute, Hamad Medical Corporation, Doha, Qatar

Correspondence to Alma Malvar Loares; aloares@moph.gov.qa

\section{ABSTRACT}

Objectives This study examines the levels of knowledge, attitude and practices (KAP) towards diabetes among Qatar nationals and long-term residents and its association with participants' selected demographics.

Setting A cross-sectional study conducted in public areas in all the eight municipalities of Qatar from July to October 2018.

Participants 2400 participants from the general public (nationals and long-term residents) stratified by gender, age and nationality across all geographic locations in Qatar.

\section{Primary and secondary outcome}

measures Responses were scored from $0 \%$ to $100 \%$ and KAP scores were classified as low $(0 \%-49 \%)$, intermediate $(50 \%-74 \%)$ or high $(75 \%-100 \%)$. Analyses and comparisons were performed using descriptive statistics and $\chi^{2}$ test at $5 \%$ level.

Results Most participants (54\%) had an intermediate overall KAP score, $43 \%$ had a low score and only $3 \%$ had a high score. The knowledge scores were the lowest among participants, $69 \%$ had low, $29 \%$ had intermediate and only $2 \%$ had high scores. Participants scored better in attitude and practice; the percentages of participants who scored high, intermediate and low were $32 \%$, $55 \%$ and $13 \%$ for attitude, and $37 \%, 33 \%$ and $30 \%$ for practice, respectively. Except for age, level of knowledge significantly varied by gender, nationality and diabetesrelated diagnosis $(p<0.001)$; attitude and practice levels differed significantly in all four factors. Areas where participants were deficient include: diabetes types, risk factors, signs and symptoms, complications, recommended daily exercise, normal fasting glucose level, preventive measures, management and control and understanding about complexity of diabetes. Conclusions Participants generally have intermediate levels of positive attitudes and practices towards diabetes but low knowledge in diabetes-related factors. The data suggest that future communications should focus on educating the public and conduct mass campaigns about diabetes to improve knowledge especially targeting men and women, and both nationals and expatriates.

\section{Strengths and limitations of this study}

- The strengths of this study include being population based having a relatively large sample, and inclusion of both Qatar nationals and expatriate participants in the sample.

- The limitation of the study is its recruitment technique from public places which might have resulted in exclusion of home-bound population, thus does not accurately represent the whole Qatar population.

\section{INTRODUCTION}

Diabetes has become a major public health threat in Qatar due to its debilitating effects on the population's quality of life and wellbeing. Diabetes and its related complications, including cardiovascular disease, kidney disease, neuropathy, blindness and lower extremity amputation, are one of the top three causes of death in Qatar. ${ }^{1}$ The Stepwise survey conducted in 2012 among Qatari nationals found that diabetes prevalence was $16.7 \%$ among adults aged 18 years and above. ${ }^{2}$ Prevalence of overweight, obesity and hypertension was $70.1 \%, 41.4 \%$ and $33 \%$, respectively. ${ }^{2}$

As the incidence of diabetes is increasing worldwide, ${ }^{3} 4$ evaluation of diabetes knowledge, attitude and practice (KAP) has become crucial for guiding behavioural changes for persons with diabetes and individuals at risk. KAP-related studies are important in tailoring a health programme to help curb the threats caused by the disease. ${ }^{5-8}$ Adequate information helps the public understand the risks of diabetes and its complications, seeks treatment of existing disease, takes preventive measures and develops proactive attitude towards health. ${ }^{9} 10$

The general aim of this study was to gauge public's KAP towards diabetes in relation to 
the diabetes awareness campaign launched by the Ministry of Public Health (MoPH) through the National Diabetes Strategy (NDS), ${ }^{11}$ which is one of the implementing arms of Qatar's National Health Strategy; aiming at reducing the incidence of diabetes and its complications in the country. Specifically, the study examined the level of KAP in diabetes-related factors and its association with selected demographic characteristics of Qatar nationals and longterm residents from the general public. As part of the initiatives of NDS, the results of the study can serve as baseline data for extending diabetes health programmes in mass campaigns to improve public KAP about the disease for diabetes prevention.

A number of diabetes-related epidemiological studies were conducted in the State of Qatar during the past 5 years. ${ }^{12-16}$ The current study, however, is the first to assess KAP from a nationwide survey of 2400 respondents from the general public consisting of Qatar nationals and longterm residents aged 18 years old and above regarding the level of KAP on various facets of diabetes. The questions encompassed general public's demographic characteristics, knowledge and attitudes towards diabetes, and lifestyle practices towards diabetes prevention, management and control. Better understanding of awareness, attitudes and perceptions towards diabetes is required for future health policy, service provision and communication campaigns so that people can be better informed and take actions in preventing diabetes. This study adds value to diabetes literature through identification of diabetes KAP-related misconceptions among the public and which segments of the community were the targets for awareness campaigns and interventions.

\section{METHODS}

A cross-sectional study was conducted on a total of 2400 Qatar nationals and long-term residents from July to October 2018 through a 30 min computer-assisted personal interview using validated and pretested English and Arabic structured questionnaires. The sample size was statistically reliable at $99 \%$ confidence level and $2.6 \%$ margins of error for representation of the different ethnic make-up of Qatar population. Participants were stratified by age, gender and nationality across all geographic locations in Qatar to ensure representativeness. Sample size specific to age and geographic location was proportional to size of Qatar's population, while disproportionate sampling was used for gender and nationality to reflect Qatar's population structure. The survey was conducted across the eight municipalities of Qatar specifically in public areas that are frequently visited by residents, including commercial roads, parks, markets, petrol stations and other places that are accessible, and public crowd is allowed in it. Response rate was $90 \%$; only those who consented were included.

Inclusion criteria for recruitment were Qatar nationals and residents who lived in the country for at least 5 years, both sexes and at least 18 years old. Excluded from the study were visitors and Qatar expatriates with residency below 5 years. The survey was part of the NDS fact-finding programmes and was conducted by MoPH for the purpose of strategy development. Ethical considerations such as obtaining informed consent from respondents prior to survey, maintaining respondents' anonymity and data confidentiality were followed. Survey participants were not identifiable and they were not contacted after the survey was completed. The anonymised data used for this research were reviewed by the Institutional Review Board of Hamad Medical Corporation, Qatar.

The questionnaire, developed by Intelligence Qatar (a market research agency based in Doha, Qatar) in consultation with the National Diabetes Committee of MoPH, underwent validation, pretesting and reliability test using Cronbach's alpha. Content validation was performed by $\mathrm{MoPH}$ subject matter experts to check the relevance of the questions in providing information about diabetes. The questionnaire was pilot tested on 50 randomly selected respondents. The items were found to be reliable with a Cronbach's alpha coefficient of 0.70 , which is considered acceptable. The diabetes KAP questionnaire included questions related to demographic characteristics, general knowledge about diabetes, agree/disagree statements for attitude and questions and subquestions for practices. For knowledge, respondents were asked about types of diabetes, normal fasting blood glucose, the recommended daily exercise and other diabetes-related information such as risk factors, signs and symptoms, complications, preventive measures and management and control of diabetes. For attitude, respondents were asked of their agreement on 11-item behaviours towards diabetes in a scale of $1-5$, where 1 is strongly disagree and 5 is strongly agree. Practice questions pertain to consultations with health professionals about diabetes-related issues, diabetes screening and participants' practices towards prevention or managing diabetes. A KAP score was developed to provide a scorecard measure to quantify the levels of KAP towards diabetes among residents of Qatar. Each correct answer was given a point score of 'one' and the wrong answer, inclusive of 'Don't Know', a score of 'zero'. Considering that the study serves as the baseline for future awareness campaign programmes, respondent scores were classified into three levels with an assumption of $50 \%$ as the passing score. Thus, cutoff points for the level of KAP scoring were as follows: $75 \%-100 \%, 50 \%-74 \%$ or $0 \%-49 \%$ for high, intermediate or low, respectively.

Descriptive statistics including frequency counts, percentages, $\chi^{2}$ test and Spearman correlation analysis were used to determine significant differences/relationships in KAP score levels according to gender, age, nationality and diabetes diagnosis at $5 \%$ level. Z-test on proportions adjusting $\mathrm{p}$ values using Bonferroni correction for pairwise comparison was used. All data were processed using SPSS V.20.0 (IBM) at 95\% confidence level. 


\begin{tabular}{lc}
\hline \multicolumn{2}{l}{ Table 1 Demographic characteristics of participants } \\
\hline Characteristics & $\mathbf{n}(\%)$ \\
\hline $\begin{array}{l}\text { Gender } \\
\text { Male }\end{array}$ \\
\hline Female & $1203(50.1)$ \\
Age (years) & $1197(49.9)$ \\
\hline $18-24$ & \\
$25-34$ & $383(16.0)$ \\
\hline $35-44$ & $956(39.8)$ \\
$45-54$ & $617(25.7)$ \\
\hline $55+$ years & $301(12.5)$ \\
Nationality & $143(6.0)$ \\
Qatar nationals & \\
\hline Arab expats & $798(33.3)$ \\
Asian expats & $903(37.6)$ \\
African expats & $601(25.0)$ \\
Western expats & $86(3.6)$ \\
\hline
\end{tabular}

\section{Patient and public involvement}

This is a cross-sectional survey of the public; no patient was involved as the survey targeted the public as the respondents. The results will be disseminated in layman's language for easy understanding by the public through local newspaper article and official social media of the MoPH.

\section{RESULTS}

\section{Participant characteristics}

The sample of 2400 participants from the general public in Qatar consisted of $50.1 \%$ males and $49.9 \%$ females. Age group representation was highest for 25-34 years $(\mathrm{n}=956,39.8 \%)$ and lowest for 55 years and above $(\mathrm{n}=143$, $6 \%$ ). The sample included long-term residents who have lived in Qatar for at least 5 years, which consisted of Arabs, Asians, Africans and Westerners. By nationality, Arab expatriates had the highest representation $(\mathrm{n}=903$, $37.6 \%)$, followed by Qatar nationals $(\mathrm{n}=798,33.3 \%)$; the least were Westerner expatriates $(\mathrm{n}=12,0.5 \%)$ (table 1$)$.

Most participants ( $\mathrm{n}=2000 ; 83 \%)$ reported that they did not have any diabetes-related diagnosis, 65 responded they do not know if they were tested for diabetes and 335 participants (14\%) reported they had a diabetes-related diagnosis: 99 reported type 2 diabetes (T2D), 74 type 1 diabetes (T1D), 9 pre-diabetes, 90 gestational diabetes and 63 did not know what kind of diabetes diagnosis they had (table 2).

\section{Overall KAP levels}

Only 3\% of participants had a high overall KAP score whereas $54 \%$ and $43 \%$ had an intermediate and low

Table 2 Overall KAP levels by gender, age, nationality and diabetes-related diagnosis

\begin{tabular}{|c|c|c|c|c|c|}
\hline \multirow[b]{2}{*}{ Characteristics } & \multirow[b]{2}{*}{$\mathbf{N}$} & \multicolumn{3}{|c|}{ KAP Level } & \multirow[b]{2}{*}{$P$ value } \\
\hline & & $\begin{array}{l}\text { High } \\
\text { n (\%) }\end{array}$ & $\begin{array}{l}\text { Intermediate } \\
\mathrm{n}(\%)\end{array}$ & $\begin{array}{l}\text { Low } \\
\text { n (\%) }\end{array}$ & \\
\hline All participants & 2400 & $71(3)$ & $1298(54)$ & $1031(43)$ & \\
\hline \multicolumn{2}{|l|}{ Gender } & & & & $<0.001^{*}$ \\
\hline Male & 1203 & $22(2)^{a}$ & $505(42)^{\mathrm{a}}$ & $676(56)^{a}$ & \\
\hline Female & 1197 & $49(4)^{b}$ & $793(66)^{b}$ & $355(30)^{b}$ & \\
\hline \multicolumn{2}{|l|}{ Age } & & & & $<0.001^{*}$ \\
\hline $18-44$ & 1956 & $58(3)^{\mathrm{a}}$ & $989(51)^{\mathrm{a}}$ & $909(46)^{\mathrm{a}}$ & \\
\hline $45-55+$ & 444 & $13(3)^{a}$ & $309(70)^{b}$ & $122(27)^{b}$ & \\
\hline \multicolumn{2}{|l|}{ Nationality } & & & & $<0.001^{*}$ \\
\hline Qatari & 798 & $14(2)^{a}$ & $431(54)^{\mathrm{a}}$ & $353(44)^{\mathrm{a}}$ & \\
\hline Arab expat & 903 & $33(4)^{a}$ & $537(59)^{\mathrm{a}}$ & $333(37)^{b}$ & \\
\hline Other nationalities & 699 & $24(3)^{a}$ & $330(47)^{b}$ & $345(50)^{a}$ & \\
\hline \multicolumn{3}{|c|}{ Self-reported diabetes-related diagnosis } & & & $<0.001^{*}$ \\
\hline Yes & $335(83 \%)$ & $27(8)^{a}$ & $211(63)^{a}$ & $97(29)^{a}$ & \\
\hline No & 2000 & $43(2)^{b}$ & $1072(54)^{b}$ & $885(44)^{b}$ & \\
\hline Don't know & 65 & $1(2)^{\mathrm{ab}}$ & $15(23)^{\mathrm{c}}$ & $49(75)^{c}$ & \\
\hline
\end{tabular}

Superscript letters $\mathrm{a}, \mathrm{b}$ and $\mathrm{c}$ denote a subset of the column variables (Z-test on proportions with Bonferroni post hoc test correction method, $p<0.05)$; in a column, values labelled with the same letter are not different but values labelled with different letters are significantly $(p<0.05)$ different from each other.

${ }^{*}$ Test of significance performed by $\chi^{2}$ test.

KAP, knowledge, attitude and practice. 


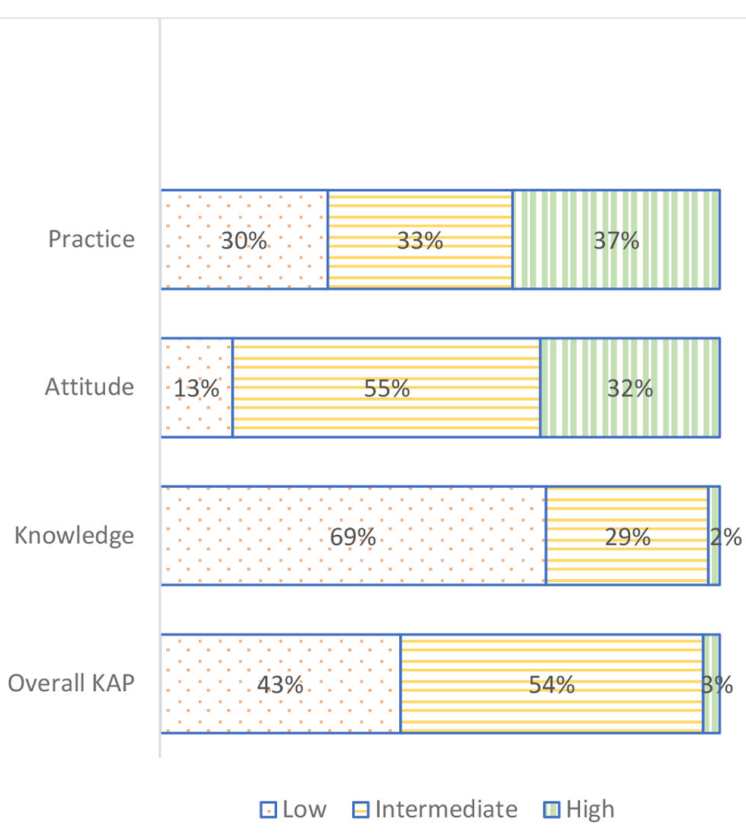

Figure 1 Percentage of participants with low, intermediate and high levels of knowledge, attitude and practice (KAP).

overall KAP score, respectively (figure 1 and table 2). Significant differences in KAP levels were noted by demographic characteristics $(\mathrm{p}<0.001)$ (table 2$)$. More than half of the men $(56 \%)$ had low KAP score while only $30 \%$ of women had a low score level. Older participants had a higher KAP score level than the younger age groups; for example, $70 \%$ of older versus $51 \%$ of younger participants having intermediate scores $(\mathrm{p}<0.05)$ and $46 \%$ of younger versus $27 \%$ of older participants having low scores $(p<0.05)$, respectively (table 2$)$. Scores differed by nationality, for example, more Qatar nationals (54\%) and Arab expatriates $(59 \%)$ than other nationalities $(47 \%)$ had intermediate KAP scores $(\mathrm{p}<0.05)$ (table 2$)$. Among the lowest score, most individuals who did not know if they have diabetes had low KAP score $(75 \%)$, followed by those who answered they did not have diabetes $(44 \%)$ as compared with those who knew they had a diabetes diagnosis $(29 \%$ ) (table 2 ).

There was a weak but significant relationship $(\mathrm{p}<0.001)$ between knowledge and attitude, knowledge and practice and attitude and practice (table 3). Participants who were more knowledgeable about diabetes and its related factors had higher tendency to exhibit better attitude and

Table 3 Correlation of the scores of knowledge, attitudes and practice of participants

\begin{tabular}{lll}
\hline Indicators & Pearson $\mathbf{r}_{\mathbf{s}}$ & P value \\
\hline Knowledge and attitude & 0.311 & $<0.001^{*}$ \\
Knowledge and practice & 0.220 & $<0.001^{*}$ \\
Attitude and practice & 0.104 & $<0.001^{*}$ \\
\hline
\end{tabular}

*Significant relationships by Spearman correlation test. practices towards diabetes prevention and management and vice versa.

\section{Knowledge gaps}

There were several critical knowledge gaps. For example, 'Diabetes can be cured' and 'Insulin is used for T1D only' are false statements, but $64 \%$ did not know that insulin may be used to treat diabetes other than type 1 and $44 \%$ were not aware of the different types of diabetes. The statement 'Type 2 diabetes can be prevented' is a true statement, but $51 \%$ of participants did not know that T2D is preventable (table 4 ).

Eight risk factors of diabetes were not commonly mentioned by the participants. Most participants were not aware of the effects of stress $(81 \%)$, smoking cigarettes or shisha $(88 \%)$, abdominal fat $(89 \%)$ and gestational diabetes $(91 \%)$, and did not know three of the most common signs and symptoms of diabetes such as feeling hungry $(82 \%)$, slow healing of wounds or cuts $(82 \%)$ and skin problems $(82 \%)$. The majority of respondents did not know that nerve damage $(78 \%)$, skin problems $(80 \%)$ and stroke $(83 \%)$ are among diabetes complications. Among the preventive measures, the majority did not know the roles of reduction of sugary drinks (70\%), stress management $(88 \%)$, screening for diabetes $(88 \%)$, eating more fruits and vegetables $(89 \%)$, smoking cessation $(89 \%)$, drinking more water $(93 \%)$ and increasing fibres in diet $(94 \%)$.

For management and control of diabetes, most participants only identified a few out of the 10 listed factors. Most participants did not correctly identify the benefits of reducing carbohydrate consumption $(86 \%)$, controlling weight $(87 \%)$, smoking cessation $(88 \%)$, ensuring regular intake of medications as prescribed $(88 \%)$, regular check-up (94\%) and foot care $(95 \%)$ (table 4$)$. It can be deduced from the aforementioned results that the public were generally not aware of the role of weight, diet, stress, smoking and foot and skin problems in the development of diabetes.

\section{KAP components and demographics}

For the individual KAP components, only $2 \%$ of participants had high knowledge whereas $29 \%$ and $69 \%$ of participants had intermediate and low knowledge, respectively. On the other hand, $32 \%$ and $37 \%$ of participants scored high in attitude and practices, respectively (figure 1 and table 5). Attitude and practice scores were significantly different in relation to gender, age and nationality whereas knowledge scores were similar among different age groups but were significantly different between males and females and among nationalities $(\mathrm{p}<0.001)($ table 5$)$. The individual KAP component scores also differed significantly between participants with and without a diabetes-related diagnosis or not. Those who had diabetes-related diagnosis had better scores than those who did not; the worse scores were among the group who were not tested for diabetes, 65 individuals representing $3 \%$ of participants. 
Table 4 Diabetes-related factors most commonly answered either correctly, incorrectly/not mentioned or not known by respondents

\begin{tabular}{|c|c|c|c|c|}
\hline Knowledge indicators & Areas of low prevalence & $\begin{array}{l}\text { Correct } \\
\text { answer (\%) }\end{array}$ & $\begin{array}{l}\text { Wrong/not mentioned } \\
(\%)\end{array}$ & Don't know (\%) \\
\hline \multirow[t]{4}{*}{ General knowledge } & $\begin{array}{l}\text { Aware with at least one type of } \\
\text { diabetes }\end{array}$ & 56 & 5 & 39 \\
\hline & Diabetes can be cured* & 37 & 53 & 10 \\
\hline & Insulin is used for T1D only* & 36 & 33 & 31 \\
\hline & $\begin{array}{l}\text { Type } 2 \text { diabetes can be } \\
\text { prevented } \dagger\end{array}$ & 49 & 18 & 33 \\
\hline Normal fasting glucose & $70-99 \mathrm{mg} / \mathrm{dL}$ & 29 & 32 & 39 \\
\hline Recommended daily exercise & $30 \mathrm{~min}$ & 44 & 45 & 11 \\
\hline \multirow{8}{*}{$\begin{array}{l}\text { Risk factors (to be mentioned } \\
\text { by respondents) }\end{array}$} & Eating unhealthy food & 42 & 59 & \\
\hline & Regularly drinking sugary drinks & 39 & 61 & \\
\hline & Family history of diabetes & 38 & 62 & \\
\hline & $\begin{array}{l}\text { Not doing enough regular } \\
\text { exercise }\end{array}$ & 32 & 68 & \\
\hline & Having high stress & 19 & 81 & \\
\hline & Smoking cigarettes or shisha & 12 & 88 & \\
\hline & Carrying most of fats in stomach & 11 & 89 & \\
\hline & Having gestational diabetes & 9 & 91 & \\
\hline \multirow{6}{*}{$\begin{array}{l}\text { Signs and symptoms (to be } \\
\text { mentioned by respondents) }\end{array}$} & Passing more urine & 49 & 51 & \\
\hline & Feeling extremely tired & 46 & 54 & \\
\hline & Always feeling thirsty & 33 & 67 & \\
\hline & Always feeling hungry & 18 & 82 & \\
\hline & Having cuts that slowly heal & 18 & 82 & \\
\hline & $\begin{array}{l}\text { Skin problems (acne, black neck, } \\
\text { etc) }\end{array}$ & 18 & 82 & \\
\hline \multirow{9}{*}{$\begin{array}{l}\text { Complications of diabetes (to } \\
\text { be identified by respondents) }\end{array}$} & Eye disease & 49 & 51 & \\
\hline & Kidney disease & 43 & 57 & \\
\hline & Foot problems & 39 & 61 & \\
\hline & Amputation & 38 & 62 & \\
\hline & Weight loss & 37 & 63 & \\
\hline & Heart disease & 35 & 65 & \\
\hline & Nerve damage & 22 & 78 & \\
\hline & Skin problems & 20 & 80 & \\
\hline & Can cause stroke & 17 & 83 & \\
\hline \multirow{8}{*}{$\begin{array}{l}\text { Preventive measures (to be } \\
\text { mentioned by respondents) }\end{array}$} & Maintain a healthy weight & 47 & 53 & \\
\hline & Reduce sugary drinks & 30 & 70 & \\
\hline & Manage stress & 12 & 88 & \\
\hline & Get screened for diabetes & 12 & 88 & \\
\hline & Eat more fruits and vegetables & 11 & 89 & \\
\hline & Stop smoking & 11 & 89 & \\
\hline & Drink more water & 7 & 93 & \\
\hline & Increase fibre in diet & 6 & 94 & \\
\hline
\end{tabular}

Continued 
Table 4 Continued

\begin{tabular}{|c|c|c|c|c|}
\hline Knowledge indicators & Areas of low prevalence & $\begin{array}{l}\text { Correct } \\
\text { answer (\%) }\end{array}$ & $\begin{array}{l}\text { Wrong/not mentioned } \\
(\%)\end{array}$ & Don't know (\%) \\
\hline \multirow{6}{*}{$\begin{array}{l}\text { Management and control of } \\
\text { diabetes (to be identified by } \\
\text { respondents) }\end{array}$} & $\begin{array}{l}\text { Avoid sugar-sweetened } \\
\text { beverages and food }\end{array}$ & 39 & 61 & \\
\hline & $\begin{array}{l}\text { Regularly check blood sugar and } \\
\text { visit to doctors }\end{array}$ & 32 & 68 & \\
\hline & Manage stress & 27 & 73 & \\
\hline & Control weight & 13 & 87 & \\
\hline & Smoking cessation & 12 & 88 & \\
\hline & $\begin{array}{l}\text { Regular intake of prescribed } \\
\text { medication }\end{array}$ & 12 & 88 & \\
\hline
\end{tabular}

${ }^{\star}$ False statement.

†True statement.

T1D, type 1 diabetes.

By gender, more female than male participants $(37 \%$ vs $20 \%$ ) had intermediate knowledge scores while more males than females (78\% vs 60\%) had low scores. By nationality, more Arab expatriates $(35 \%)$ than other nonArab expats (25\%) and Qataris (25\%) had intermediate scores while a higher proportion of Qataris (74\%) and non-Arab expats (72\%) than Arab expats (63\%) had low knowledge scores.

In terms of attitude, more women (36\%) than men $(28 \%)$ had high scores while more men $(19 \%)$ than women $(7 \%)$ had low scores. Younger participants with low attitude scores were more than twice than the older respondents (15\% vs $7 \%$ ). More Arab expats $(38 \%)$ had high attitude scores while more non-Arab expats (59\%) had intermediate scores than their counterparts. Participants who did not know if they have diabetes-related diagnosis had the least number of high and intermediate scores and four times more than those who are aware of their diabetes-related diagnosis to have low attitude scores.

More male than female participants (33\% vs $28 \%$ ) had low practice scores. More older participants $(51 \%)$ had high practice scores while more of younger participants $(33 \%)$ had low scores than the older ones $(20 \%)$. More non-Arab expats (42\%) had high practice scores than the Arab expats and Qataris. More participants who did not know if they were tested for diabetes had low practice scores than those who reported they were aware of their diabetes-related diagnosis.

On the other hand, several positive aspects emerged from the current findings; most participants reported positive attitudes towards diabetes prevention and management including having had their blood glucose level tested for diabetes (67\%) and consulted a healthcare professional during the past year (68\%). A greater proportion also adhere to healthy lifestyle practices including drinking $>8$ glasses of water daily $(71 \%)$, monitoring weight regularly $(68 \%)$, participating in at least $30 \mathrm{~min}$ of moderate to intense physical exercise (65\%), not smoking (63\%), conscious healthy eating (58\%), actively lowering salt consumption $(55 \%)$ and following a diet plan (53\%). Two-thirds $(67 \%)$ of the participants do not regularly consume sugary drinks and $63 \%$ do not eat sweet foods; only $46 \%$ did regular health check-ups (figure 2).

\section{DISCUSSION}

This study provides analysis of knowledge, attitudes and practices towards diabetes of the nationals and long-term residents from the general public in Qatar as it relates to selected demographic variables including gender, age and nationality.

Contradictory findings were reported regarding KAP in Qatar, few studies reported good or high knowledge ${ }^{617-19}$ whereas others reported low levels of knowledge. ${ }^{20}$ The inconsistent findings regarding knowledge may reflect small and biased sampling. Our study which included a relatively large sample from the general public showed low knowledge in diabetes-related factors across gender, nationality and diabetes diagnosis, and revealed that knowledge levels significantly varied by demographic factors and by diabetes diagnosis. We did not find a significant association between knowledge and age, which is different from other studies in different populations which showed that older age groups are associated with high diabetes knowledge. ${ }^{21} 22$ On the other hand, attitude and practice showed better scores among older group, female gender and Arabic or Qatari background. Our finding that women have better diabetes knowledge than 


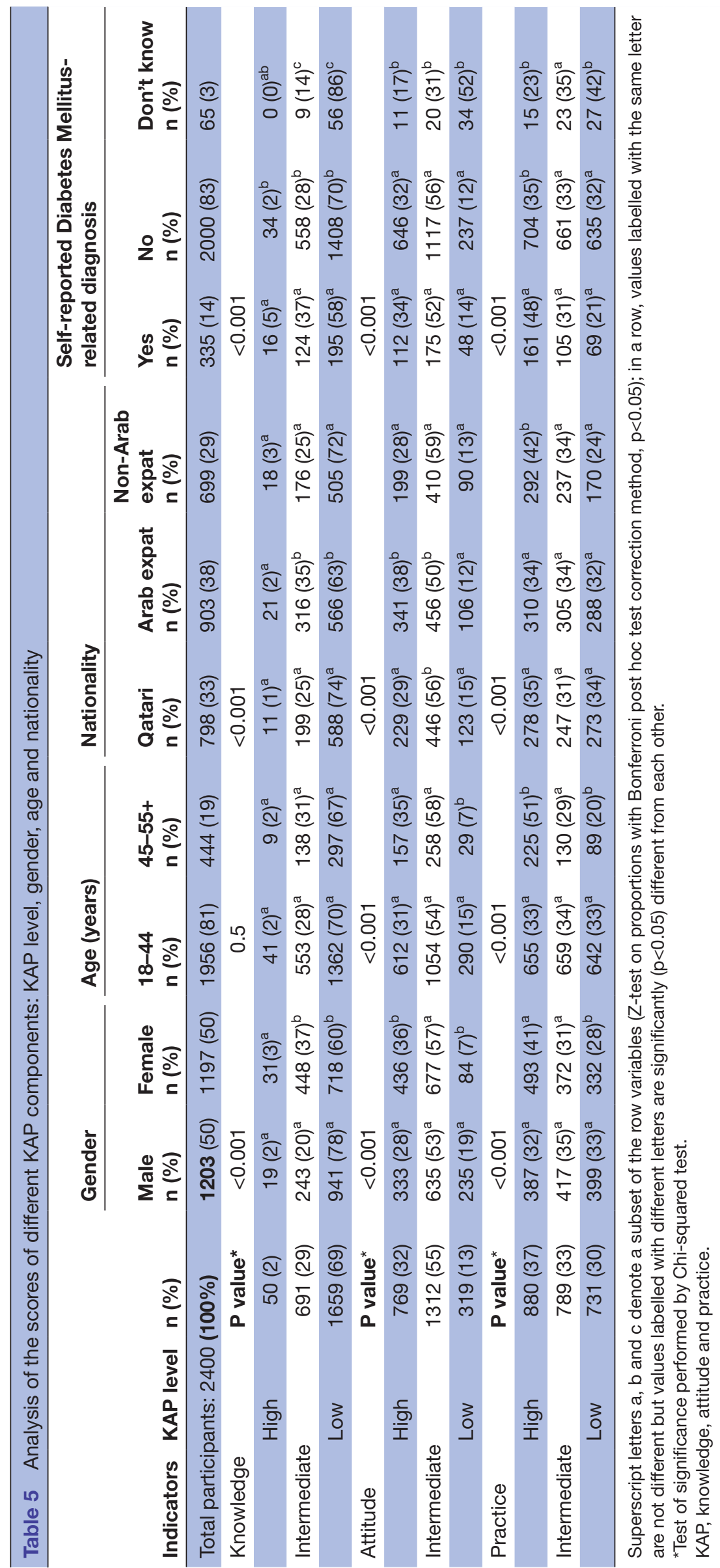




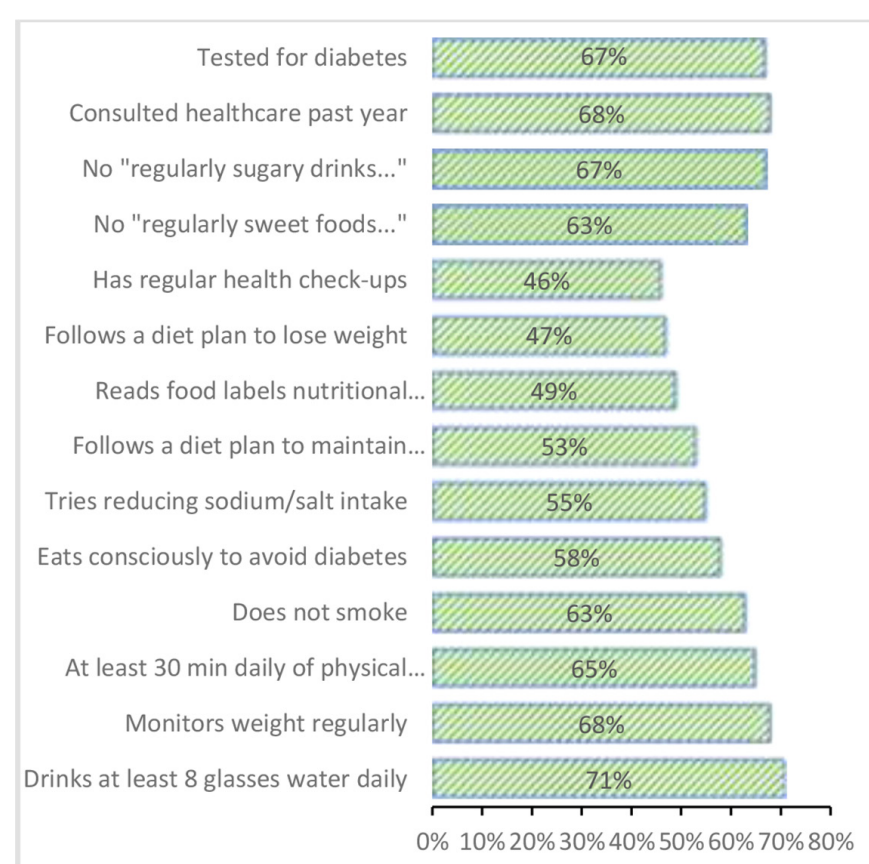

Figure 2 Percentage of participants who correctly answered questions related to lifestyle practices and attitudes towards diabetes prevention.

men is different from the findings in some countries, such as Pakistan, Bangladesh and Saudi Arabia, where men were reported to have a higher diabetes knowledge than women, ${ }^{23-25}$ but similar to the findings in India and China showing greater diabetes awareness among women than men. ${ }^{26}{ }^{27}$ The gender disparity in the KAP score in this study reflects the facts that only women report a history of gestational diabetes, which is highly prevalent among pregnant women in Qatar and estimated to be $23 \%$ of all pregnancies. ${ }^{28}$ The high rate of gestational diabetes in Qatar can be explained by the higher percentage of overweight or obese women at the start of their pregnancy (between $70 \%$ and $80 \%$ ). ${ }^{28}$

The present study showed that diabetes screening significantly associates with increased KAP level; and evidence showed that persons with diabetes have better KAP than those without diabetes. ${ }^{29}$ Taken together, we can conclude that implementation of a national screening for diabetes at a country like Qatar, where diabetes is highly prevalent among adults, shall contribute to increased KAP towards diabetes.

The significant associations between KAP towards diabetes in this study agree with other studies. ${ }^{17} 3031$ It suggests that a better knowledge is likely to result in better attitude and/or practices towards diabetes prevention.

The present finding generally showed an intermediate KAP score for attitude and practice but poor in knowledge across participants' characteristics. The better KAP score for attitude and practice may be ascribed to the health promotion activities initiated by the different health sectors in the country, which contribute to improving the public's attitude and practices towards healthy living. Qatar has developed its own dietary guidelines advocating good eating habits and physical activity through various initiatives. ${ }^{32}$ Likewise, physical activity is encouraged at all age groups ${ }^{33}$ and a lot of activities on tobacco control are implemented in all sectors. ${ }^{34}$ These initiatives are working on the risk factors such as diet, physical activity and smoking, in which residents and citizens actively participate in; however, respondents may not be aware that these activities are directly impacting diabetes.

One of the significant contributions of this study was the identification of commonly held knowledge gaps about diabetes in Qatar population, which were related to the role of individual risk factors in diabetes development such as role of stress, smoking, visceral fats and history of gestational diabetes; low knowledge of signs and symptoms including feeling hungry, slow healing of wounds and having skin problems; and low knowledge of complications such as nerve damage, skin problems and stroke. Low knowledge can influence the public's attitude causing complacency and passiveness instead of being proactive in diabetes prevention. Having a good knowledge, positive attitude and proactive adherence to healthy behaviour towards diabetes are initial steps towards prevention and early intervention to address the diabetes epidemic. A public health focus on diabetes prevention through public awareness about the disease including modifiable risk factors is far better than the therapeutic interventions for diabetes.

The above findings suggest targeting awareness campaigns to men, Qatar nationals and non-Arab expatriates. National screening for diabetes, as planned in the Qatar NDS, shall also contribute to the improvement in KAP score of the population. On the other hand, behavioural practices towards diabetes prevention, management and control should be enhanced and encouraged among men, younger people, Qatar nationals and Arab expatriates, and individuals who do not know if they were tested for diabetes or not. Increasing awareness on the role of weight, food intake, stress, smoking and foot and skin problems in the development and management of diabetes should be given preferential attention in future education campaigns.

The strengths of this study include being population based and the inclusion of both Qatar nationals and expatriate participants. The limitation of the study is its recruitment technique from public places which might have resulted in exclusion of home-bound population, thus does not accurately represent the whole Qatar population.

\section{CONCLUSIONS}

The present study provides baseline measures for gauging improvements in diabetes knowledge, attitudes and practices over time in Qatar population including Qatar nationals and expatriate residents. The study demonstrates that most participants have low knowledge regarding diabetes and its related factors but exhibit positive attitudes and practices towards diabetes prevention 
and management and identified KAP gaps and target populations. This finding is significant for the NDS in developing tailored communication strategies. The findings are particularly beneficial to policy makers and project implementers in targeting population at risk through the gaps in knowledge, attitudes and practices identified in the current study to address the diabetes menace, which is one of the major health concerns in Qatar society. Future communications should focus on initiating effective mass campaigns including use of digital channels and social media, which may have special impact on the younger population, to improve diabetes knowledge of the general public and those with diabetes especially targeting men and women, young people and both nationals and expatriates.

Acknowledgements The authors would like to thank the National Diabetes Committee and the Ministry of Public Health for the support for the survey, the Intelligence Qatar for facilitating data collection and the survey participants for their support provided.

Contributors MA-T, KAA-M and A-BA-S did the writing, review and editing of the manuscript. AHF and RN did the report writing and review of the paper. AML did the questionnaire construction, data processing, analysis and report writing. IS did the reference citations and facilitated paper revision. KAA-M and A-BA-S served as advisors and guarantors.

Funding The authors have not declared a specific grant for this research from any funding agency in the public, commercial or not-for-profit sectors.

Competing interests None declared.

Patient and public involvement Patients and/or the public were not involved in the design, or conduct, or reporting, or dissemination plans of this research.

Patient consent for publication Not applicable.

Ethics approval This study involves human participants. This survey was an integral part of the fact finding of Qatar National Strategy which was run by the National Diabetes Strategy, authorised by MoPH. The survey was anonymous. Informed consent from participants was sought before partaking in the survey. Subjects were not identifiable and they were not contacted after the survey was conducted. The anonymised data used for this research were reviewed by the Institutional Review Board of Hamad Medical Corporation, Qatar.

Provenance and peer review Not commissioned; externally peer reviewed.

Data availability statement Data are available upon reasonable request. Data are available upon reasonable request from the National Diabetes Strategy, Ministry of Public Health, Doha, Qatar.

Open access This is an open access article distributed in accordance with the Creative Commons Attribution Non Commercial (CC BY-NC 4.0) license, which permits others to distribute, remix, adapt, build upon this work non-commercially, and license their derivative works on different terms, provided the original work is properly cited, appropriate credit is given, any changes made indicated, and the use is non-commercial. See: http://creativecommons.org/licenses/by-nc/4.0/.

\section{ORCID iDs}

Aiman Hussein Farghaly http://orcid.org/0000-0002-6660-0821

Alma Malvar Loares http://orcid.org/0000-0001-7677-2558

\section{REFERENCES}

1 National health strategy 2018-2022. Available: https://www.moph. gov.qa/english/strategies/National-Health-Strategy-2018-2022/ Pages/default.aspx

2 Qatar stepwise report 2012. Available: https://www.who.int/ncds/ surveillance/steps/Qatar_2012_STEPwise_Report.pdf?ua=1

3 World health statistics, WHO, 2021. Available: https://www.who.int/ news-room/fact-sheets/detail/diabetes

4 IDF diabetes atlas 9th edition, 2019. Available: https://www. diabetesatlas.org/en/sections/worldwide-toll-of-diabetes.html
5 Ardeňa GJRA, Paz-Pacheco E, Jimeno CA, et al. Knowledge, attitudes and practices of persons with type 2 diabetes in a rural community: phase I of the community-based diabetes selfmanagement education (DSME) program in San Juan, Batangas, Philippines. Diabetes Res Clin Pract 2010;90:160-6.

6 Herath HMM, Weerasinghe NP, Dias H, et al. Knowledge, attitude and practice related to diabetes mellitus among the general public in Galle district in southern Sri Lanka: a pilot study. BMC Public Health 2017; $17: 535$

7 Kassahun T, Gesesew H, Mwanri L, et al. Diabetes related knowledge, self-care behaviours and adherence to medications among diabetic patients in Southwest Ethiopia: a cross-sectional survey. BMC Endocr Disord 2016;16:28.

8 Kueh YC, Morris T, Borkoles E, et al. Modelling of diabetes knowledge, attitudes, self-management, and quality of life: a cross-sectional study with an Australian sample. Health Qual Life Outcomes 2015;13:129.

9 Fatema K, Hossain S, Natasha K, et al. Knowledge attitude and practice regarding diabetes mellitus among nondiabetic and diabetic study participants in Bangladesh. BMC Public Health 2017;17:364.

10 Moodley LM, Rambiritch V. An assessment of the level of knowledge about diabetes mellitus among diabetic patients in a primary healthcare setting. South African Family Practice 2007;49:16-16d.

11 Qatar national diabetes strategy 2016-2022. Available: https:// www.moph.gov.qa/english/strategies/Supporting-Strategies-andFrameworks/nationaldiabetesstrategy/Pages/default.aspx

12 Al-Kaabi SK, Atherton A. Impact of noncommunicable diseases in the state of Qatar. Clinicoecon Outcomes Res 2015;7:377-85.

13 Al-Thani A-A, Farghaly A, Akram H, et al. Knowledge and perception of diabetes and available services among diabetic patients in the state of Qatar. Cent Asian J Glob Health 2019;8:333.

14 Al-Thani M, Al-Thani A-A, Al-Chetachi W, et al. Situation of diabetes and related factors among Qatari adults: findings from a communitybased survey. JMIR Diabetes 2017;2:e7.

15 Ali FMH, Nikoloski Z, Reka H, et al. The diabetes-obesityhypertension nexus in Qatar: evidence from the world health survey. Popul Health Metr 2014;12:18.

16 Dargham SR, Shewehy AE, Dakroury Y, et al. Prediabetes and diabetes in a cohort of Qatari women screened for polycystic ovary syndrome. Sci Rep 2018;8:3619.

17 Al-Thani A-A, Farghaly AH, Akram H, et al. Public awareness and perceptions about diabetes in the state of Qatar. Cureus 2018; $10: \mathrm{e} 2671$

18 Alsous M, Abdel Jalil M, Odeh M, et al. Public knowledge, attitudes and practices toward diabetes mellitus: a cross-sectional study from Jordan. PLoS One 2019;14:e0214479.

19 Jackson IL, Adibe MO, Okonta MJ, et al. Knowledge of self-care among type 2 diabetes patients in two states of Nigeria. Pharm Pract 2014;12:404.

20 Perera DP, De Silva REE, Perera WLSP. Knowledge of diabetes among type 2 diabetes patients attending a primary health care clinic in Sri Lanka. East Mediterr Health J 2013;19:644-8.

21 Aljofan M, Altebainawi A, Alrashidi MN. Public knowledge, attitude and practice toward diabetes mellitus in hail region, Saudi Arabia. Int J Gen Med 2019;12:255-62.

22 Dorner TE, Lackinger C, Schindler K, et al. Health information regarding diabetes mellitus reduces misconceptions and underestimation of consequences in the general population. Public Health Nutr 2013;16:2032-9.

23 Fatema K, Hossain S, Natasha K, et al. Knowledge attitude and practice regarding diabetes mellitus among nondiabetic and diabetic study participants in Bangladesh. BMC Public Health 2017; $17: 364$

24 Islam SMS, Niessen LW, Seissler J, et al. Diabetes knowledge and glycemic control among patients with type 2 diabetes in Bangladesh. Springerplus 2015;4:284.

25 Memon MS, Shaikh SA, Shaikh AR, et al. An assessment of knowledge, attitude and practices (KAP) towards diabetes and diabetic retinopathy in a suburban town of karachi. Pak J Med Sci 2015;31:183-8.

26 Hussain R, Rajesh B, Giridhar A, et al. Knowledge and awareness about diabetes mellitus and diabetic retinopathy in suburban population of a South Indian state and its practice among the patients with diabetes mellitus: a population-based study. Indian J Ophthalmol 2016;64:272-6.

$27 \mathrm{Li} \mathrm{J}, \mathrm{Ni} \mathrm{J}, \mathrm{Wu} \mathrm{Y}$, et al. Sex differences in the prevalence, awareness, treatment, and control of diabetes mellitus among adults aged 45 years and older in rural areas of northern China: a cross-sectional, population-based study. Front Endocrinol 2019;10:147.

28 Koley M, Saha S, Arya JS, et al. Knowledge, attitude, and practice related to diabetes mellitus among diabetics and nondiabetics 
visiting homeopathic hospitals in West Bengal, India. J Evid Based Complementary Altern Med 2016;21:39-47.

29 Karbalaeifar R, Kazempour-Ardebili S, Amiri P, et al. Evaluating the effect of knowledge, attitude and practice on self-management in patients with type 2 diabetes. Acta Diabetol 2016;53:1015-23.

$30 \mathrm{Ku}$ GMV, Kegels G. Knowledge, attitudes and perceptions of people with type 2 diabetes as related to self-management practices: results of a cross-sectional study conducted in Luzon, Philippines. Chronic IIIn 2015;11:93-107.

31 Deepa M, Bhansali A, Anjana RM, et al. Knowledge and awareness of diabetes in urban and rural India: the Indian Council of medical research India diabetes study (phase I): Indian Council of medical research India diabetes 4. Indian J Endocrinol Metab 2014;18:379-85.

32 Qatar dietary guidelines, 2015. Available: https://www.moph.gov.qa

33 Qatar national physical activity first edition, 2014. Available: https:// www.namat.qa/Namatlmages/Publications/75/QATAR\%20PA\% 20GUIDLINE\%20ENGLISH.PDF

34 Who EMRO 2021 tobacco free initiative. Available: http://www. emro.who.int/tfi/news/qatar-bans-waterpipes-creates-nationalawareness-and-adapts-smoking-cessation-services-during-covid19.html 